\title{
"Eu, professora" em face da implementação da Política Nacional de ampliação do Ensino Fundamental na rede municipal de Curitiba, PR
}

\section{"I'm a school teacher" facing the National Policy implementation of expanding Elementary Education in the municipal chain of Curitiba, PR}

\author{
Catarina Moro ${ }^{1}$
}

\begin{abstract}
RESUMO
Neste artigo se discute a visão de professoras acerca do vivido em decorrência da implementação do Ensino Fundamental de 9 anos. Trata-se de estudo qualitativo, na perspectiva da Psicologia Histórico-cultural. Foram realizadas entrevistas individuais com seis professoras do $1^{\circ}$ Ano do Ensino Fundamental de 9 anos, da Rede Municipal de Curitiba. A análise das entrevistas teve como base a metodologia de Núcleos de Significação, proposta por Aguiar (2000, 2006) e Aguiar e Ozella (2006). A discussão focaliza o núcleo "Eu, professora" constituído para a interpretação da visão das professoras, articulado ao indicador "Sentimentos, dificuldades e soluções", que desvelam, a partir de singularidades próprias, o modo como as professoras sentem e enfrentam a realidade decorrente da implementação da Lei $n^{\circ}$ 11.274/06. Os relatos indicam um grande hiato entre a experiência vivenciada e as expectativas das professoras quanto às condições necessárias para a efetivação de práticas educativas adequadas. Nesse processo de implementação da política de ampliação do Ensino Fundamental, parece não se ter atentado para o fato de que as crenças e pensamentos dos professores trazem implicações para a implantação das políticas em geral (MAINARDES, 2006; SANTOS;
\end{abstract}

DOI: $10.1590 / 0104-4060.41366$

1 Universidade Federal do Paraná, Setor de Educação. Curitiba, Paraná, Brasil. Rua General Carneiro, n 460. CEP: 80.060-150.E-mail: moro.catarina@gmail.com 
VIEIRA, 2006; GOMES, 2005; SAMPAIO; MARIN, 2004; BARRETO; MITRULIS, 1999), o que não é diferente para essa política, em específico.

Palavras-chaves: Ensino Fundamental de 9 anos; professor; Núcleos de Significação; sentidos; implementação da política.

\begin{abstract}
In this article the view of teachers about living in result of the implementation of 9 school years in Elementary Education is discussed. This is a qualitative study, on the perspective of Historical-Cultural Psychology. Individual interviews were made with six teachers from the first year of the 9 years Elementary Education, from the municipal chain of Curitiba. The interviews analysis was based on the Cores of Meaning methodology proposed by Aguiar (2000, 2006) and by Aguiar and Ozella (2006). The debate focuses the core "I'm a school teacher" constituted in order to understand the teachers' views articulated to the issue "Feelings, problems and solving", which reveal through their own singularities the way those teachers feel and face the reality since the implementation of the 11.274/06 Law. The reports indicate a great distance between the experience they had and their hopes about the necessary conditions to effect appropriate educational practices. In that process of implementing the enlargement of school years in Elementary Education policies, the fact that the beliefs and thoughts of teachers bring consequences to introduce policies in general was not noticed (MAINARDES, 2006; SANTOS; VIEIRA, 2006; GOMES, 2005; SAMPAIO; MARIN, 2004; BARRETO; MITRULIS, 1999), which is not different for that specific law.
\end{abstract}

Keywords: 9 years Elementary Education; teachers; Cores of Meaning; senses; policy implementation.

Sem dúvida nenhuma o professor é figura central no debate educacional, nem sempre do modo como, sobretudo, os programas oficiais e as políticas públicas o colocam. O professor, ao mesmo tempo em que produz uma educação no "chão" da escola, vai tendo sua história, seu papel e sua função marcados pelas condições do contexto social, político e profissional do qual faz parte. Discutindo questões relativas ao ofício de professor, diferentes autores realçam marcas que têm configurado a profissão e seu exercício cotidiano, entre as quais se destaca aqui uma parte: a hiper-responsabilização (GIMENO-SACRISTÁN, 1995); o isolamento (CANÁRIO, 1998); a desvalorização (NÓVOA, 1999); o impasse entre desistência x resistência (CALDAS, 2007); a feminização da profissão (PENNA, 2007); o distanciamento da profissão das elites econômicas (KNOUBLACH, 2008; PENNA, 2007); entre outras. 
O presente texto discute parte dos dados construídos por ocasião da realização da pesquisa de doutorado da autora ${ }^{2}$ com respeito à visão das professoras acerca das realidades por elas vivenciadas no tocante às mudanças referentes à implementação do Ensino Fundamental, reestruturado para 9 anos de duração. Tratou-se de estudo qualitativo, de caráter compreensivo e interpretativo, tendo como pressuposto orientador a perspectiva da Psicologia Histórico-cultural.

Elegeu-se como instrumento e procedimento principal no campo empírico, para a construção dos dados de análise, a entrevista individual, semiestruturada, que foi desenvolvida com base em um roteiro com perguntas abertas. Para análise das entrevistas, buscou-se a definição de um tratamento com contornos e procedimentos próprios, tendo como base os trabalhos de Aguiar $(2000,2006)$ e de Aguiar e Ozella (2006) acerca da metodologia de nuclearização dos significados.

\section{As professoras: Beatriz, Cintia, Fernanda, Maria Luiza, Paula e Tayane}

Buscou-se a interlocução com professores, especificamente professoras, no caso das participantes deste estudo ${ }^{3}$, da Rede Municipal de Educação de Curitiba $^{4}$ (RME-Ctba), que estivessem vivenciando em seu cotidiano a proposta de reestruturação da Educação Básica nacional e fossem responsáveis por turmas de $1^{\circ}$ ano.

As seis participantes da pesquisa eram todas mulheres ${ }^{5}$, tinham em comum o fato de todas terem formação superior e a formação inicial antecedente, em

2 MORO, Catarina de Souza. Ensino Fundamental de 9 anos: o que dizem as professoras do $1^{\circ}$ ano. 315 f. Tese (Doutorado) - Setor de Educação, Universidade Federal do Paraná, Curitiba, 2009.

3 Nas escolas contatadas para a coleta de dados da presente pesquisa não havia profissionais do sexo masculino, como regentes de sala, no quadro docente. Existiam professores homens apenas em Educação Física.

4 A RME - Curitiba contava, em 2008, com 173 estabelecimentos escolares para atendimento educacional nas modalidades e níveis envolvendo: Educação Infantil, Ensino Fundamental, Educação Especial e Educação de Jovens e Adultos. Para acompanhamento das atividades desenvolvidas nessas unidades escolares e para efetivação das suas próprias ações, a Secretaria Municipal de Educação segue a descentralização proposta pela Prefeitura, dividindo a cidade em nove Administrações Regionais.

5 Com isso, a função profissional assume no texto o gênero feminino e passa-se a partir de então a utilizar os termos professora e professoras. A fim de se resguardar o anonimato das participantes, pediu-se que cada uma escolhesse um nome fictício que viria a constar no texto da pesquisa (uma das professoras deixou a cargo da pesquisadora esta escolha). Os nomes escolhidos pelas professoras têm histórias particulares e significados pessoais que ficaram resguardados a elas. $\mathrm{Na}$ tese, a fim de dar a conhecer cada participante nas suas singularidades e reconhecer suas inserções nessa atuação que lhes é comum, traz-se a apresentação de cada uma separadamente, com base no que elas indicaram no momento das entrevistas. 
nível Médio, que lhes concedeu a habilitação em Magistério. As seis professoras tinham entre 31 e 47 anos, sendo a média de idade 40 anos. Maria Luiza e Paula não têm filhos. Tayane, Cintia, Fernanda e Beatriz ${ }^{6}$ têm dois filhos cada uma.

Quatro professoras concluíram a formação inicial em instituição pública (uma delas fez o curso Normal Superior ofertado em parceria entre a Secretaria Municipal de Educação e uma universidade pública ${ }^{7}$ ), duas cursaram instituição particular. Entre as habilitações estavam: o curso de Pedagogia, concluído por quatro professoras; o curso Normal Superior, para outra, e o curso de Letras, também por uma professora. Cinco professoras concluíram cursos de Pós-graduação lato sensu, entre os anos de 1998 e 2004, sempre em instituição particular, sendo que Beatriz fez especialização em Psicopedagogia; Cintia, Maria Luiza e Fernanda fizeram especialização em Educação Infantil e Séries Iniciais e Tayane fez especialização em Alfabetização.

Os dados acerca dos cursos de especialização permitem inferir que sua oferta por instituições públicas, locais, está aquém da demanda; nenhuma das professoras do grupo cursou pós-graduação lato sensu em instituição pública. O ônus com o curso de Especialização se dá em âmbito individual, o que por vezes significa uma despesa alta em relação à percepção salarial de cada uma.

O tempo médio de docência entre as professoras era de 18 anos, sendo o menor tempo de experiência de 13 anos e o maior, 21 anos, ou seja, nenhuma estava em início de carreira. Todas as professoras referiram ter a intenção de manter-se futuramente na mesma carreira e função. Metade do grupo - Cintia, Fernanda e Paula - trabalhava dois períodos na própria Rede Municipal. A outra metade - Tayane, Maria Luiza e Beatriz - trabalhava um período. Nenhuma das professoras desenvolvia outra atividade remunerada, além da docência.

Em relação à experiência com as duas primeiras etapas da Educação Básica, todas as professoras vivenciaram a docência na Educação Infantil e no Ensino Fundamental. O tempo de trabalho com crianças com até 6 anos de idade estava entre 2 e 12 anos de atuação. De algum modo esse dado suscita expectativas de que tal experiência permitiria a cada uma trazer para o trabalho com o novo $1^{\circ}$ ano do Ensino Fundamental aspectos considerados importantes para a(s) infância(s) e que não incorram em uma escolarização precocizada, pouco significativa para as crianças, agora mais jovens e pertencentes à "grande escola”. (PLAISANCE, 2004).

6 A filha mais nova de Beatriz, no ano de 2008, frequentava o $1^{\circ}$ ano do Ensino de 9 anos em uma escola particular.

7 O curso era oferecido exclusivamente para professores da Rede Municipal que ainda não tinham formação superior específica para atuação com as séries iniciais. Mescla formação inicial com formação em serviço. A modalidade era a distância, semipresencial. 
Os dados apresentados acima permitem uma ideia sobre o perfil das participantes revelando que todas já perfizeram metade do tempo da carreira; a maioria tem especialização e se encontra, de acordo com seus próprios depoimentos, radicada na profissão.

Para análise dos dados partiu-se da constituição de indicadores com vistas à construção dos Núcleos de Significação, "momento [em] que, efetivamente, iniciamos o processo de análise e avançamos do empírico para o interpretativo, apesar de todo o procedimento ser, desde o início da entrevista, um processo construtivo/interpretativo". (AGUIAR; OZELLA, 2006, p. 8). No presente texto, discute-se exclusivamente o Núcleo de Significação ${ }^{8}$ "Eu, professora" e seu Indicador Final - "Sentimentos, dificuldades e soluções".

\section{Eu, professora}

Este núcleo, constituído para a análise, articula-se ao indicador final, desvelando o modo como as professoras sentem e enfrentam a realidade que têm vivido, a partir das suas singularidades. Assim, não estão exclusivamente relacionados às especificidades das crianças mais novas, agora pertencentes ao Ensino Fundamental, e discutidas no Núcleo de significação "Ideias sobre as crianças", ou às repercussões em âmbito pedagógico e curricular relativas à reestruturação do Ensino Fundamental, propostas no núcleo de significação "Obrigatoriedade de Matrícula um ano antes"; ambas discutidas na tese.

\section{Condições para o trabalho - aspectos estruturais e relacionais}

Dentre aspectos que representam dificuldades para o trabalho com as crianças no $1^{\circ}$ ano do Ensino Fundamental, alguns se relacionam às condições materiais, ao modo como é organizado o uso dos espaços e do tempo e outros à dinâmica e às interações no ambiente escolar relacionadas aos processos de trabalho.

8 Outros dois núcleos foram produzidos e identificados na composição do trabalho de tese, sendo: "Infância na escola", que agregou dois indicadores: "Ideias sobre as crianças" e "Brincar e aprender", e "Obrigatoriedade de matrícula um ano antes", com quatro outros indicadores: "Incerteza quanto à mudança", "A centralidade da alfabetização", "As orientações oficiais" e "Mudanças relacionadas". 
Sobre os primeiros aspectos, as participantes destacam problemas em relação à estrutura física da escola, o mobiliário, o material didático, pois mesmo reconhecendo ter havido algumas mudanças sobre seu estado, em geral, continuam precários.

Diversos pesquisadores se preocuparam com condições adversas no ofício de professor, mas não versaram sobre o espaço físico no qual o professor trabalhava, como: Codo (1999), Silvany-Neto et al. (2000), Reis et al. (2006), Gasparini, Barreto e Assunção (2005), Lapo e Bueno (2003) e Caldas (2007). Entretanto, há fortes indicativos de que esse aspecto contribui com a sensação de insatisfação e impotência do professor.

A minha sala ela é com carteira normal... para a faixa etária maior. Dignas de uma turma de $3^{a}{ }^{\ldots}$.. muitos ficam com a perninha balançando... Então o mobiliário, de repente teria que ser adaptado. (CINTIA).

[...] a minha sala é muito pequenininha. É apertadinha... Aquela sala não tem condições. E o barulho, a poluição sonora. É o barulho e eu tenho que alfabetizar nessas condições. [do lado da sala tem o] espaço para ter aula de educação física. [...] no início do ano eu fiquei bastante perturbada... É muito ruido. E agora eu consegui me adaptar ao barulho! Pode um negócio desses?! Eu me adaptei ao barulho... mas tem dias que eu fico assim, sabe, até as próprias crianças... a gente fica... perdidos. Eles desconcentram "total", eu me perco, eu não sei o que estou falando. Isso mexe comigo, sabe!!... Eu queria uma sala normal. [...] E agora estão pintando as salas... sabe, mas eu tive que me adaptar a essas condições. [...] mas eu estou insatisfeita com a sala. (TAYANE).

Reformas e manutenção deveriam representar soluções para dificuldades como as relatadas e citadas acima, sendo que nas escolas públicas tornam-se mais um fator negativo. $\mathrm{O}$ empreendimento de reformas em plena atividade letiva, como anunciado por Tayane e reafirmado por Fernanda e Maria Luiza, se soma às dificuldades pré-existentes; podendo se arrastar, como referido por Maria Luiza, por um ano escolar praticamente inteiro. Existem riscos de comprometimento da saúde física ${ }^{9}$, assim como existe o comprometimento, de fato, do trabalho pedagógico com as turmas.

9 Não se teve informações sobre ocorrência de algum prejuízo físico, seja para as crianças ou para as professoras, decorrente das alterações no ambiente provocado pelas reformas e/ou manutenção dos prédios escolares naquelas circunstâncias. 
MORO, C. "Eu, professora” em face da implementação da Política Nacional de ampliação...

[...] por conta dessa construção, dessa reforma que está tendo na escola, é... As aulas de educação física estão até sendo com turmas reduzidas. [...] isso deixa muito a desejar, assim, porque as nossas crianças precisam de movimentos, espaço. (FERNANDA).

[...] você quer sair, fazer um joguinho, só tem a quarta-feira e... agora que a escola está em construção, a gente só pode ficar dentro da sala de aula. $O$ ano passado até tinha a quarta-feira. A gente saía, montávamos brincadeiras lá fora. [...] Mas este ano não dá. Este ano está muito dificil de trabalhar [a reforma está se estendendo praticamente pelo ano inteiro]. (MARIA LUIZA).

Com relação à legítima manifestação de indignação por parte de Tayane e com base nas Notas de Campo citadas a seguir, pode-se inferir que há uma despreocupação ou descaso quanto ao ensalamento para as turmas das crianças mais novas, do Pré ou do $1^{\circ}$ ano. A sala utilizada pela turma desta professora durante o ano de 2008, segundo seu relato, havia sido do Pré anteriormente.

A sala de aula é anexa ao prédio original, menor que as demais e apegada a um espaço que se constitui no pátio coberto da escola (ao lado da cancha de esportes aberta). Possui uma janela pequena e uma porta que dá para esse pátio coberto, há duas prateleiras para acomodar todo o material. [No dia da entrevista] a sala estava recém-pintada. Havia muito pó espalhado pelo chão, pelas prateleiras (estavam fora de lugar, para ficar distantes das paredes), nos materiais. A professora se disse frustrada por ter tido os trabalhos das crianças retirados das paredes, sem nenhum cuidado e largados pelo mobiliário da sala. Refere não ter sido solicitado a eles (usuários da sala) que guardassem ou retirassem seus materiais com antecedência... (Notas de Campo).

Ainda que tais serviços sejam necessários e vitais para a continuidade do atendimento escolar, como é possível desconsiderar que ao ocorrerem em pleno período letivo acabam por acarretar inúmeros problemas e dificuldades para toda a comunidade escolar?

Além desses aspectos relativos ao espaço e à estrutura física das escolas, outras questões despontam como tensões a serem resolvidas ou como algo dado sobre o qual nada se pode fazer. O modo de cada professora interpretá-las é 
particular, estando em sintonia com suas concepções de criança, de sociedade e de educação.

Sobre a organização do tempo e ainda do espaço, tem-se a preocupação com o estabelecimento de uma rotina que as próprias professoras têm dúvidas sobre se é ou não adequada para aquele ano de escolaridade, ao serem consideradas as especificidades e necessidades das crianças (alguns desses aspectos perpassaram ou estiveram explicitados nos trechos das entrevistas já citados e nos que ainda serão apresentados a seguir).

[...] a gente está tendo bastante apoio da equipe pedagógica, da equipe administrativa [refere-se às conquistas para melhoria do espaço físicoparquinho]... eu acho que o horário ainda deixa a desejar, porque a gente só tem um horário durante a semana para levá-los até lá. (FERNANDA).

Não há menção, nas entrevistas, sobre encaminhamentos coletivos que pudessem alterar as definições estabelecidas: se o tempo ou o número de vezes que as turmas de $1^{\circ}$ ano podem usar o parque ou outro espaço escolar amplo e coletivo não é adequado, por que não discutir a possibilidade de fazer alterações em relação a isso? Essa ausência de redefinições no coletivo pode ter relação com a "tendência centralizadora" posta na "cultura da escola", como discutido por Kramer e Nunes (2007). Ou ainda com a cultura escolarizante que desvaloriza o trabalho com as "culturas da infância" e a multiplicidade de representações simbólicas, importantes para as crianças pequenas. Os professores que reconhecem essa necessidade no cotidiano educativo do $1^{\circ}$ ano, diante da impossibilidade de verem suas necessidades e das crianças acolhidas, expressam angústia e frustração em sua ação de educar.

\section{Formação continuada}

A formação continuada é reconhecida como uma necessidade e valorizada como uma solução para algumas inseguranças e incertezas perante essa nova realidade. Tal aspecto é visto tanto como já tendo respondido a algumas demandas das professoras, quanto como resposta para a continuidade de um trabalho adequado para com o $1^{\circ}$ ano. 
Muito embora todas as professoras entrevistadas reconheçam a necessidade e validade da formação contínua, o sentido atribuído a esse processo se diferencia bastante. Para algumas professoras, é revestido de um sentido pragmático, na modalidade de oficinas, caracterizando a capacitação como uma forma de gerar instrumentos, insumos, estratégias que possibilitem sempre ter atividades diferenciadas para realizar com as crianças. Pode-se articular esse modo de ver a formação com a caricatura da realização com as crianças da "atividade pela atividade", em que se deixa de lado o fato da ação de educar implicar uma ação e um saber "teorizador, compósito e interpretativo", como destaca Roldão (2007, p. 101).

É... ter mais oficinas mesmo, porque... Eu escuto que os professores estão um pouco perdidos, assim, não sabem o que fazer... (FERNANDA).

Trabalho com a alfabetização, principalmente, e trabalho com a prática, trabalhar matemática com material concreto... mais, atividades lúdicas para trabalhar.. oficinas, sabe. Esses cursos muito teóricos são bons, são importantes, mas é bom ter oficinas. (CINTIA).

Algumas professoras assumem a formação continuada como um processo para se qualificarem (independentemente da forma como essa capacitação venha a fazer parte da sua rotina - como obrigatoriedade por parte da Rede Municipal ou como curso oportunamente escolhido por ela) e se autoavaliarem com condições de assumirem-se autoras de seu próprio fazer. (GOULART, 2007).

Até para falar em reuniões de pais... a gente tava com dificuldade para falar. Então esta capacitação ajudou a gente a ter uma base [...] eu acho que nem deveria ser obrigatório, porque são coisas importantes para a gente. Me sinto um pouco mais informada e preparada em comparação com o ano passado... Mas eu sinto que ainda falta muita coisa. (PAULA).

Eu acho que depende muito do professor, de correr atrás, de buscar, foi o que eu fiz... corri atrás... através da internet que na escola tem... livros, biblioteca pública, livros... Ainda bem que a Prefeitura oferece esses cursos, né. Mas eu ia correr atrás de cursos pagos se não oferecessem. (TAYANE). 
Nas falas citadas a respeito do modo como, principalmente, Tayane e Paula parecem compreender a busca de atualização, sobre seus posicionamentos diante dos processos de capacitação que vivenciam, está claro que essas professoras tomaram para si essa responsabilização, a título de dever pessoal, individual. (GASPARINI; BARRETO; ASSUNÇÃO, 2005). Entretanto, o protagonismo assim manifesto pode ao mesmo tempo fomentar a hiper-responsabilização e o isolamento do professor (NÓVOA, 1999; CANÁRIO, 1998) e desresponsabilizar os gestores das redes municipais e/ou dos estabelecimentos escolares em assegurar trabalhos institucionais e coletivos com finalidade formativa. (FREITAS, 2003).

\section{Parcerias no trabalho}

O estabelecimento de parcerias no trabalho, seja entre professores ou entre professores e coordenação/direção, visto ora como dificuldade ora como forma de enfrentamento, é tratado por todas as professoras. Não é algo natural, sequer fácil de ocorrer, pois requer mediação.

Pesa muito esta troca de experiência que nós fazemos. Aqui na escola tem uma equipe muito boa de professores... todos os professores do primeiro ano eles se ajudam. (PAULA).

[...] a gente não tem o material de apoio, um livro, então você tem que ir buscar várias atividades. O bom nesse momento é que a gente troca com as colegas. [...] Essa troca envolve mais a gente, as quatro [professoras] do primeiro ano. (MARIA LUIZA).

Eu não consigo. [estabelecer trocas com outras professoras do $1^{\circ}$ ano, que trabalham à tarde]... é dificil contato com as minhas colegas. A gente se encontra de vez em quando e fala uma coisa e outra... Eu não sei como é que elas estão... [...] talvez a pedagoga pudesse estar mais presente. [...] é muita burocracia... eu acho dificil mesmo, ser pedagoga é dificil mesmo... É muito burocrático o trabalho dela e eu sinto só essa falta... a gente fica um pouco insegura [...] Desanimo, entendeu? Eu preciso de uma palavra de uma pedagoga, da minha diretora. Eu preciso de um 
estímulo... E, às vezes, dá a impressão que você está abandonada... [...] Eu gosto de me sentir valorizada como professora. Eu estou dando tudo de mim. (TAYANE).

Todos os depoimentos acima anunciam e denunciam a importância de se considerar as condições e os processos concretos de trabalho a que estão submetidos os professores nos diferentes contextos. Ficam desveladas as complexas relações interpessoais travadas nesses contextos, muitas vezes contraditórias, mas vivenciadas em silêncio, a fim de evitarem-se maiores conflitos.

Falta um "articulador", de fato, para o trabalho, que se proponha a criar o contexto de grupo, seja entre professores do mesmo ano escolar ou entre os professores dos diferentes anos. Altenfelder (2006) relata que essa necessidade foi apontada pelas professoras participantes do processo de intervenção realizado por ela. Para Tayane, esse espaço cabe à pedagoga da escola, mas ao mesmo tempo ela dimensiona a complexidade e os obstáculos para que isso aconteça. Resta então o desejo, exposto na entrevista, em forma de apelo, da parceria individual, que dê conta de valorizar (ou não) o trabalho que cada um realiza, que reconheça o trabalho que ela, professora, realiza.

Tayane credita ao seu trabalho como professora alto valor simbólico. Desvela-se para ela ser uma profissão que exige muita dedicação, esforço, abnegação para a melhoria das condições de vida futura das crianças. (PENNA, 2007; GATTI, 2000).

Corro atrás, sabe. Procuro livros, empresto livros... Para dar o melhor para essas crianças... Eu acho que depende de mim. [...] Eu ir atrás, porque eu me preocupo muito com essas crianças, eu quero um futuro melhor para elas, sabe. [...] estarem em uma escola pública não é porque vai aprender de qualquer maneira ou deixar para lá, não. Eu quero tudo de bom para eles, então vou atrás, eu corro atrás, eu sou dedicada, sabe, e... Tudo por eles! (TAYANE).

Acercando-se novamente de uma dimensão prática associada ao trabalho de professor, Beatriz faz referência a uma vicissitude decorrente dos sentidos atribuídos à finalidade do $1^{\circ}$ ano do Ensino Fundamental de 9 anos. Ao estar atrelado à apropriação da cultura escrita pelas crianças, acaba por impingir ou impor contrassensos à prática educativa dos professores. 
[...] eu tive oportunidade de sentir isso como mãe também, porque minha filha foi para o primeiro ano [está em escola particular]... ai eu recebi um bilhete da professora para ela frequentar o turno contrário, segunda, quarta e sexta teria aula de reforço. [...] Ela frequentou um periodo de um mês, um mês e pouquinho... as aulas do turno da manhã, uma hora e meia e dai como ela não faltou, como eu fiquei ali, em cima, ela, a partir de hoje, não precisava ir mais. [...] Ela [filha] falou: "Mãe, mas por que é que eu vou para a aula de manhã, mãe?" "Mas dai eu vou ter que ir de tarde de novo" [os colegas não iam no contraturno]. (BEATRIZ).

Aqui o disparate é o risco da criança pequena, recém-admitida no Ensino Fundamental, estar sendo considerada atrasada e ser exposta a atividades "de reforço", sem nenhum diferencial em relação ao modo como se trabalha em sala. Outro contrassenso se refere ao fato de as crianças perderem as poucas aulas "especiais" ou os horários para brincar, que em geral são oportunidades para trabalhar com movimentos e com o corpo.

Beatriz, como professora e mãe, sente um estranhamento diante dessa situação, mas assente a ela: "Há que se recuperar o que está em atraso!", muito embora caibam muitas perguntas: O que estaria de fato acontecendo? A mediação, as estratégias do professor não são interessantes a ponto de que "a alquimia da apropriação" referida por Roldão (2007, p. 101) sobre aquele conhecimento aconteça com a criança?

Beatriz, no papel de professora, revela estar muito angustiada com as exigências que compreende serem exageradas, em função da idade e da condição socioeconômica das crianças e de suas famílias. Sente-se mal diante das cobranças feitas a ela e que, ainda que discordando, ela repassa às crianças. Diz sentir-se uma "mísera" "roubando a infância dessas crianças". Contudo, ela parece encontrar certo apaziguamento quando verifica que esse sentimento não é só dela.

Foi proporcionado para nós encontros [por Regionais] e foi dada abertura para cada uma colocar aquilo que sentia, as dificuldades que encontrava [...] Nessa troca eu pude perceber que a angústia não era só minha. (BEATRIZ).

Beatriz deixa transparecer em sua entrevista estar sendo afetada pelo processo de desistência, decorrente das suas vivências anteriores e das muitas 
vicissitudes do processo de implementação do Ensino Fundamental de 9 anos que tem experimentado.

[...] eu senti que estava roubando a infância dessas crianças... é uma situação bem angustiante... Então, eu adoro trabalhar com essa faixa etária, mas eu estou me sentindo, assim, impotente, porque tem coisas que não dependem só de mim [...] É tão prazeroso ver o progresso deles e a gente acaba pulando uma etapa aí desse aprendizado aí... Então me corta o coração. Tem um aluno que chega pra mim e todo dia "plofessola você é monita". Sabe, ao mesmo tempo que aquilo é gratificante, é emocionante, é... Dolorido, porque ele já não deveria estar falando assim. [...] como eu estou muito angustiada, né, porque eu me preocupo muito com as crianças, eu estou pensando em pedir uma outra função para o ano que vem. Só que eu não consegui definir qual ainda. (BEATRIZ).

Tayane, ao contrário, busca recuperar não apenas a valorização do seu trabalho, mas o prestígio necessário à escola pública, implicado na postura ética dos profissionais nela envolvidos. A forma como tem sentido e vivido o trabalho com o $1^{\circ}$ ano (revelado em várias das suas falas) lhe dá força para resistir, perseverar.

[...] eu não desanimo. Eu penso sempre nas crianças, eles estão na escola pública, tem muito professor bom aqui. Tem muita gente boa, muito pedagogo bom, que se importa com você. (TAYANE).

As interpretações e análises até aqui desenvolvidas apontam para uma grande distância entre a experiência com o $1^{\circ}$ ano, as expectativas de cada professora e as condições consideradas por elas como necessárias para a efetivação de práticas educativas adequadas. Em meio a esse desencontro, se assomam questões gerais da profissão, independentes da situação específica da regência do $1^{\circ}$ ano. Entre elas, o relacionamento com os pais das crianças, a necessária e intrincada parceria com os colegas e coordenação, a expectativa em ter seu trabalho reconhecido e valorizado, entre outras. A formação continuada é entendida como obrigação e instrumento para o enfrentamento dos constantes desafios profissionais.

Existe uma contradição inerente ao processo de implementação do Ensino Fundamental de 9 anos vivenciado por Beatriz, Cintia, Fernanda, Maria Luiza, 
Paula e Tayane, responsável pelos desencontros sentidos por elas. Apesar de lhes trazer uma nova realidade, não foi desse modo a elas anunciado. A presença da criança mais jovem e o encaminhamento pedagógico ou das práticas educativas, tendo implícitas as diretrizes curriculares para o referido ano escolar, foram dispostos ao corpo docente como uma situação conhecida, antiga, frente à qual todo professor saberia como reagir e da qual se sabia o que esperar. Afinal, era "a mesma turma de pré", houve só "mudança na nomenclatura".

Tanto não foi assim, que exatamente esse novo lugar, simbólico, que a criança de 6 anos ou menos passou a ocupar, em decorrência da Lei n ${ }^{\circ} 11.274 / 06$, indicou às professoras participantes deste estudo as novas expectativas demandadas pelos contextos social ou extraescolar e escolar ou intraescolar. A fim de entender, negociar e/ou cumprir com essas expectativas, as professoras se depararam com dúvidas, tensões, imposições, tomadas de decisão próprias, descobertas, impossibilidades e várias nuances de sentimentos provocados pelas vivências particulares e/ou comuns entre elas.

Algumas dificuldades identificadas e enfrentadas pelas professoras na prática educativa, se possível, são resolvidas por elas mesmas, ao lançar mão de estratégias e recursos diferenciados afinados com os interesses e necessidades das crianças. Outras dificuldades estruturais (por exemplo, espaço físico, materiais) e/ou organizativas, que dependam do contexto escolar como um todo (por exemplo, horários para uso da área externa, do parque), são em geral alvo de queixas; mas são suportadas, neutralizadas na medida do possível até que se finalize o ano letivo. Não foram entendidas como passíveis de solução.

$\mathrm{O}$ apoio pedagógico que as professoras receberam foi importante para todas elas, mas para algumas parece não ter sido suficiente para dirimir as dúvidas, os impasses, assim como as angústias decorrentes da nova realidade. Nesse sentido as oportunidades de discutir e expressar dificuldades, opiniões, insatisfações e dúvidas foram insuficientes para ressignificá-las.

É preciso destacar que as professoras referem verem-se praticamente sozinhas na realização de seu trabalho. Apesar de haver investimento na formação continuada, até então elas tiveram como exclusividade a temática da alfabetização a qual não acontece no contexto da própria escola. Se foram feitas parcerias, foi por iniciativa das próprias professoras, as quais tiveram essa "sorte" em meio à dinâmica complexa das relações de trabalho intraescolares. Seja ou não reflexo das políticas que reforçam o individualismo e a ideia de que cada um é isoladamente responsável pela qualidade do seu trabalho (KRAMER; NUNES, 2007; GASPARINI; BARRETO; ASSUNÇÃO, 2005; FREITAS, 2003), o que parece acometer algumas professoras é uma enorme solidão. Nos contextos escolares considerados para esta pesquisa, não existiam encaminhamentos coletivos na própria instituição para que as professoras refletissem e discutissem 
suas práticas, problematizando-as e buscando meios comuns para efetivar as modificações necessárias e desejadas.

O locus de trabalho, a escola, não era vivenciado, e quem sabe sequer considerado como espaço de desenvolvimento profissional. No intuito de ressignificar a escola, seria imperativo o redimensionamento da função de coordenação, do pedagogo, para que esse profissional realmente atuasse como articulador e líder desse processo.

O caráter da formação em serviço ou continuada aqui referido implicaria criar grupos de trabalho, de estudos e de discussão, como ações geradas a partir do interior da escola. E não somente ter algum professor/instrutor para repassar conteúdos teóricos e/ou teórico-práticos acerca do que o professor do $1^{\circ}$ ano precisaria fazer. (SARTURI, 2008; GORNI, 2007). Assim, o professor poderia repensar a mediação pedagógica que tem efetivado com as crianças desse ano escolar no sentido de avaliar se ela vem ocorrendo do modo adequado e não apenas se vem obtendo os resultados esperados.

Constata-se também a existência de um conflito entre as condições idealizadas para o acolhimento da criança mais jovem em suas necessidades e as condições concretas, reais, encontradas nas instituições. Provavelmente, não tendo ambiência para compartilhar suas emoções perante a concretude do contexto escolar, essas se somam a outras questões e produzem uma sensação de mal-estar. Sensação esta que, muitas vezes, repercute ciclicamente de modo negativo para o trabalho das professoras, dando a elas a sensação de ineficiência, incompetência, impotência.

Foi claramente sinalizado pelas entrevistadas que a política do ensino de 9 anos, na visão delas, contribui para a elevação dos padrões de acesso, o que para parte das professoras significa igualar oportunidades e oferecer justiça social para com o segmento da população educado na escola pública e, para outra parte, significa mascarar as diferenças entre a educação privada e a pública, por desconsiderar as diversidades entre seus públicos. Isso implica que a política de ampliação do Ensino Fundamental, e sua consequente antecipação, continue reproduzindo desigualdades: mais precocemente as crianças, principalmente no segmento público, poderão manifestar a histórica dificuldade com a apropriação da linguagem escrita.

\section{À guisa de considerações quanto ao percurso realizado}

Entende-se que este estudo qualitativo, constituído por intermédio de entrevistas com seis professoras de três escolas da Rede Municipal de Educação 
de Curitiba, trouxe entre outras uma questão importante sobre o papel dos professores na implementação das políticas educacionais. Destarte, a compreensão de Mainardes (2006, p. 53) de que "[...] os professores e demais profissionais exercem um papel ativo no processo de interpretação e reinterpretação das políticas educacionais e, dessa forma, o que eles pensam e no que acreditam têm implicações para o processo de implementação das políticas", no processo de implementação vivido pelas participantes, não considerou seu papel ativo.

Os relatos referentes às dificuldades e soluções perante a realidade do $1^{\circ}$ ano, sistematizadas no núcleo "Eu, professora", indicam um grande hiato entre a experiência vivenciada e as expectativas das professoras quanto às condições necessárias para a efetivação de práticas educativas adequadas. São comuns sentimentos de insatisfação e indignação com questões gerais da profissão, entre elas: a inexistência de parceria com os colegas e com a coordenação ou com os pais das crianças e a expectativa por reconhecimento e valorização de seu trabalho. A formação é considerada uma obrigação e, ao mesmo tempo, uma possibilidade para o enfrentamento dos constantes desafios vivenciados pelas professoras.

Depreende-se dos dados das entrevistas que não se atentou, nesse processo de implementação, para o fato de que a percepção, as crenças e os pensamentos dos professores trazem várias implicações para a implementação das políticas em geral, e dessa, em específico.

\section{REFERÊNCIAS}

AGUIAR, W. M. J. de. Reflexões a partir da psicologia sócio-histórica sobre a categoria "consciência". Cadernos de Pesquisa, São Paulo, n. 110, p. 125-142, jul. 2000.

AGUIAR, W. M. J. de. A Pesquisa junto a professores: fundamentos teóricos e metodológicos. In: AGUIAR, W. M. J. de. Sentidos e significados do professor na perspectiva sócio-histórica: relatos de pesquisa. São Paulo: Casa do Psicólogo, 2006. p. 11-22.

AGUIAR, W. M. J. de; OZELLA, S. Núcleos de significação como instrumento para a apreensão da constituição dos sentidos. Psicologia: ciência e profissão, Brasília, v. 26, n. 2, p. 1-22, jun. 2006.

ALTENFELDER, A. H. Formação continuada: os sentidos atribuídos na voz do professor. In: AGUIAR, W. M. J. de. Sentidos e significados do professor na perspectiva sócio-histórica: relatos de pesquisa. São Paulo: Casa do Psicólogo, 2006. p. 41-58.

BARRETO, E. S. de SÁ; MITRULIS, E. Os ciclos escolares: elementos de uma trajetória. Cadernos de Pesquisa, São Paulo, n. 108, p. 27-48, nov. 1999. 
CALDAS, A. do R. Desistência e resistência no trabalho docente: um estudo das professoras e professores do ensino fundamental da rede municipal de educação de Curitiba. Tese (Doutorado em Educação) - Universidade Federal do Paraná, Curitiba, 2007.

CANÁRIO, R. A escola: o lugar onde os professores aprendem. Revista do Programa de Estudos Pós-Graduados em Psicologia da Educação da PUC-SP, São Paulo, n. 6, $1^{\circ}$ sem., p. 9-27, 1998.

CODO, W. Educação: carinho e trabalho. Petrópolis: Vozes; CNTE, 1999.

FREITAS, H. C. L. de. Certificação docente e formação do educador: regulação e desprofissionalização. Educação \& Sociedade, Campinas, v. 24, n. 85, p. 1095-1124, dez. 2003.

GASPARINI, S. M.; BARRETO, S. M.; ASSUNÇÃO, A. A. O professor, as condições de trabalho e os efeitos sobre sua saúde. Educação e Pesquisa, São Paulo, v. 31, n. 2, p. 189-199, maio/ago. 2005.

GATTI, B. Formação de professores e carreira: problemas de movimento e renovação. Campinas: Autores Associados, 2000.

GIMENO-SACRISTÁN, J. Consciência e ação sobre a prática como libertação profissional dos professores(as). In: NÓVOA, A. (Org.). Profissão professor. Porto: Porto Editora, 1995.

GOMES, C. A. Desseriação escolar: alternativa para o sucesso? Ensaio: Avaliação e Políticas Públicas em Educação, Rio de Janeiro, v. 13, n. 46, p. 11-38, jan./mar. 2005.

GORNI, D. A. P. Ensino fundamental de 9 anos: estamos preparados para implantá-1o? Ensaio: Avaliação e Políticas Públicas em Educação, Rio de Janeiro, v. 15, n. 54, p. 67-80, jan./mar. 2007.

GOULART, C. Crianças de seis anos na escola de nove anos: cultura lúdica e cultura escrita sem antagonismos. In: SEMINÁRIO LINGUAGENS EM EDUCAÇÃO INFANTIL, 5., 2007, UNICAMP, Campinas. COLE - Congresso de Leitura. Disponível em: $<$ http://www.alb.com.br/anais16/prog_pdf/prog13_02a.pdf>. Acesso em: 07 maio 2008.

KNOUBLACH, A. Aprendendo a ser professora: um estudo sobre a socialização profissional de professoras iniciantes no município de Curitiba. Tese (Doutorado em Educação) - Pontifícia Universidade Católica de São Paulo, São Paulo, 2008.

KRAMER, S.; NUNES, M. F. Gestão pública, formação e identidade de profissionais de educação infantil. Cadernos de Pesquisa, v. 37, n. 131, p. 423-454, ago. 2007.

LAPO, F. R.; BUENO, B. O. Professores, desencanto com a profissão e abandono do magistério. Cadernos de Pesquisa, São Paulo, n. 118, p. 65-88, mar. 2003.

MAINARDES, J. Abordagem do ciclo de políticas: uma contribuição para a análise de políticas educacionais. Educação \& Sociedade, Campinas, v. 27, n. 94, p. 47-69, jan./ abr. 2006. 
MORO, C. "Eu, professora” em face da implementação da Política Nacional de ampliação...

NÓVOA, A. Os professores na virada do milênio: do excesso dos discursos à pobreza das práticas. Educação e Pesquisa, São Paulo, v. 25, n. 1, p. 11-20, jan./jun. 1999.

PENNA, M. G. de O. Professor de séries iniciais do ensino fundamental em escolas públicas estaduais de São Paulo: posições sociais e condições de vida e trabalho. Tese (Doutorado em Educação) - Pontifícia Universidade Católica de São Paulo, São Paulo, 2007.

PLAISANCE, E. Para uma sociologia da pequena infância. Educação \& Sociedade, Campinas, v. 25, n. 86, p. 221-241, abr. 2004.

REIS, E. J. F. dos et al. Docência e exaustão emocional. Educação \& Sociedade, Campinas, v. 27, n. 94, p. 229-253, jan./abr. 2006.

ROLDÃO, M. C. Função docente: natureza e construção do conhecimento profissional. Revista Brasileira de Educação, v. 12, n. 34, p. 94-103, jan./abr. 2007.

SAMPAIO, M. das M. F.; MARIN, A. J. Precarização do trabalho docente e seus efeitos sobre as práticas curriculares. Educação \& Sociedade, Campinas, v. 25, n. 89, p. 1203 1225, set./dez. 2004.

SANTOS, L. L. de C. P.; VIEIRA, L. M. F. Agora seu filho entra mais cedo na escola: a criança de seis anos no ensino fundamental de nove anos em Minas Gerais. Educação \& Sociedade, Campinas, v. 27, n. 96, p. 753-774, out. 2006.

SARTURI, R. C. O Ensino fundamental de nove anos: em busca da legitimação das políticas públicas no cotidiano escolar. In: ENCONTRO NACIONAL DA ANPAE, 23., 2007. Anais... 2007. Disponível em: <http://www.isecure.com.br/anpae/391.pdf>. Acesso em: 11 nov. 2008.

SILVANY-NETO, A. M. et al. Condições de trabalho e saúde dos professores da rede particular de ensino na Bahia. Revista Baiana de Saúde Pública, Salvador, v. 24, n. 3/4, p. 42-56, 2000.

Texto recebido em 14 de maio de 2015. Texto aprovado em 11 de outubro de 2015. 